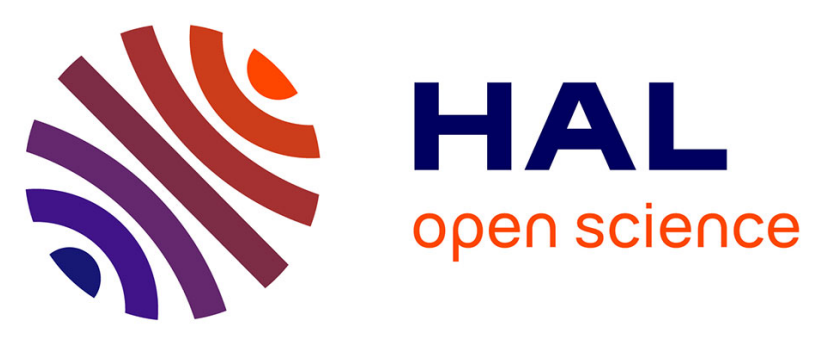

\title{
Room Temperature Magnetic Switchability Assisted by Hysteretic Valence Tautomerism in a Layered Two-Dimensional Manganese-Radical Coordination Framework
}

\author{
Anthony Lannes, Yan Suffren, Jean Bernard Tommasino, Rodica Chiriac, \\ François Toche, Lhoussain Khrouz, Florian Molton, Carole Duboc, Isabelle \\ Kieffer, Jean-Louis Hazemann, et al.
}

\section{- To cite this version:}

Anthony Lannes, Yan Suffren, Jean Bernard Tommasino, Rodica Chiriac, François Toche, et al.. Room Temperature Magnetic Switchability Assisted by Hysteretic Valence Tautomerism in a Layered Two-Dimensional Manganese-Radical Coordination Framework. Journal of the American Chemical Society, 2016, 138 (50), pp.16493-16501. 10.1021/jacs.6b10544 . hal-01419234

\author{
HAL Id: hal-01419234 \\ https://hal.science/hal-01419234
}

Submitted on 27 Apr 2021

HAL is a multi-disciplinary open access archive for the deposit and dissemination of scientific research documents, whether they are published or not. The documents may come from teaching and research institutions in France or abroad, or from public or private research centers.
L'archive ouverte pluridisciplinaire HAL, est destinée au dépôt et à la diffusion de documents scientifiques de niveau recherche, publiés ou non, émanant des établissements d'enseignement et de recherche français ou étrangers, des laboratoires publics ou privés. 


\section{Room Temperature Magnetic Switchability Assisted by Hysteretic Valence Tautomerism}

in a Layered Two Dimensional Manganese-Radical Coordination Framework

Anthony Lannes§, Yan Suffrenł†, Jean Bernard Tommasino§, Rodica Chiriac§, François Toche§, Lhoussain Khrouzf, Florian Molton!, Carole Duboc!, Isabelle Kiefferæ\#, Jean-Louis Hazemannæ $\diamond$, Christian Reber $\perp$, Andreas Hauser $¥$, and Dominique Luneau§*

$\S$ Univ Lyon, Université Claude Bernard Lyon 1, Laboratoire des Multimatériaux et Interfaces, UMR CNRS 5615, F69622, Villeurbanne, France.

‡ Département de chimie physique, Université de Genève, 30 Quai Ernest-Ansermet, 1211 Genève 4, Switzerland.

† Present address: Institut des Sciences Chimiques de Rennes (UMR CNRS-INSA 6226) - INSA-Rennes - 20 Avenue des Buttes de Coësmes, CS 70839, 35708 Rennes Cedex 7, France

S Univ Lyon, Ens de Lyon, CNRS UMR 5182, Université Claude Bernard Lyon 1, Laboratoire de Chimie, F69342, Lyon, France

I Département de Chimie Moléculaire (UMR 5250), Université Joseph Fourier, Grenoble, France

× BM30B/FAME beamline, European Synchrotron for Research Facility (ESRF), Grenoble, France

\# Observatoire des Sciences de l'Univers de Grenoble (OSUG), CNRS UMS 832, 414 rue de la piscine, 38400 Saint Martin d'Hères, France

$\diamond$ Institut Néel, UPR 2940 CNRS, Grenoble, France

$\perp$ Département de Chimie, Université de Montréal, Montréal, Canada.

Keywords: manganese, nitronyl-nitroxide, valence tautomerism, magnetism, solid-state absorption, electronic paramagnetic resonance, $\mathrm{X}$-ray spectroscopy

ABSTRACT: The manganese-nitronyl-nitroxide two dimensional coordination polymer $\{[\mathrm{Mn} 2(\mathrm{NITIm}) 3] \mathrm{ClO} 4\} \mathrm{n}$ (1) (NITImH = 2-(2-imidazolyl)-4,4,5,5-tetramethyl-4,5-dihydro-1H-3-oxide-1-oxyl) undergoes an unusual hysteretic thermo-induced valence tautomeric transition near room temperature, during which the manganese(II) ions are oxidized to manganese(III) and two of the three deprotonated radicals (NITIm-) are reduced to their diamagnetic aminoxyl form (denoted NITImRed2-). Upon cooling, the high-temperature species $\{[\mathrm{MnII2}(\mathrm{NITIm}) 3] \mathrm{ClO} 4\} \mathrm{n}(1 \mathrm{HT})$ turns into the lowtemperature species $\{[\mathrm{MnIII2}$ (NITImRed)2(NITIm)]ClO4\}n (1LT) around $274 \mathrm{~K}$, while on heating the process is reversed at about $287 \mathrm{~K}$. This valence tautomeric phenomenon is supported by temperature-dependent magnetic susceptibility measurements, differential scanning calorimetry (DSC), crystal structure determination, UV-vis absorption, X-ray absorption (XAS) and emission (XES) and Electron Paramagnetic Resonance (EPR) spectroscopies in the solid-state. 


\section{INTRODUCTION}

Developing bistable systems responding to external stimuli such as heat, magnetic fields or light is of high scientific interest and important for technological purposes. Such systems are relevant for novel applications in switches, sensors, signal processing and information storage.1-8 Potential candidates are valence tautomeric (VT) complexes, consisting of a redox-active metal center coordinated to non-innocent ligands.9-11 VT transitions have their origin in the capacity of switching the metal-to-ligand electronic charge distribution reversibly between two redox isomers. The first example was reported by Pierpont et al. in 1980, in a cobalt(III) complex bearing a catecholate (CAT) ligand.12 In this redox process, the Co(III) ion is reduced to Co(II) and the CAT ligand is oxidized to its semiquinonato (SQ) form. VT transitions involving SQ-CAT ligand are by far the most reported in the literature, mainly in Co, 12-27 and Mn isolated com-

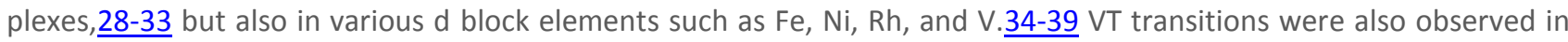
four unidimensional (1D) and one Co-based bidimensional (2D) coordination polymers. $\underline{32}, \underline{40-43}$ Other ligands than SQCAT are less common in VT systems, with a dozen examples reported so far, involving porphyrin derivatives, cyclopentadienyl, or bis(diisopropyl-phenylimino)acenaphthene.44-55In the latter case VT was reported for Yb.55

Nitroxide radicals are potentially redox-active and may be reversibly oxidized to an oxoammonium cation, or reduced to an aminoxyl anion (Scheme 1). $\underline{56}$ However, they have generally been considered to be stable, even when coordinated to metal ions. This is especially true for the nitronyl-nitroxide (NIT) radicals where the radical is delocalized across both NO groups. $\underline{57}$

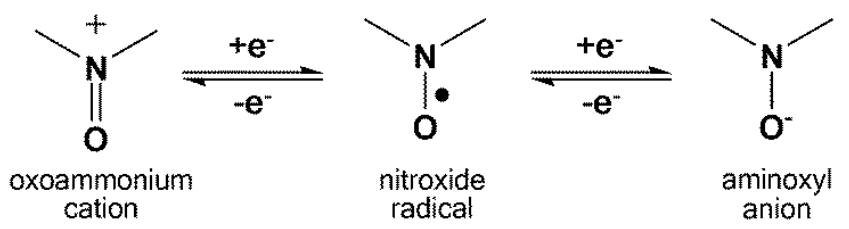

Scheme 1. Redox isomers of the nitroxide radical.

The stability of NIT radicals, combined with their bridging ability, has greatly contributed to their extensive use as spin carriers for the efficient building of molecule based magnets, based on the so-called metal radical approach. $\underline{58}$ Exploiting this approach, we have developed chelating NITs especially with imidazole (NITImH) and benzimidazole (NITBzImH) substituents, $\underline{59}$ for the synthesis of discrete complexes with $\mathrm{d} \underline{60}$ and $\underline{61} \underline{61-65}$ metal ions as well as $1 \mathrm{D} \underline{66}$ and $2 \mathrm{D}$ coordination $\underline{67}, \underline{68}$ polymers. The 2D polymer $\{[\mathrm{Mn} 2(\mathrm{NITBz} / \mathrm{m}) 3] \mathrm{ClO} 4\} \mathrm{n}$, obtained with NITBzImH and manganese(II) perchlorate can be described as a layered compound and behaves as a ferrimagnet with a Curie temperature Tc $=55 \mathrm{~K}$, the highest reported so far for NIT-based compounds. $\underline{59}$ Changing the radical to NITImH as shown in Scheme 2 (NITImH = 2-(2-imidazolyl)-4,4,5,5-tetramethyl-4,5-dihydro-1H-3-oxide-1-oxyl) yields the analog compound $\{[\mathrm{Mn} 2(\mathrm{NITIm}) 3] \mathrm{ClO} 4\} \mathrm{n}$ (1) that displays a similar structure, but a notable difference in its magnetic properties, with a remanent magnetization observed only below 1.4 K.․ㅡ

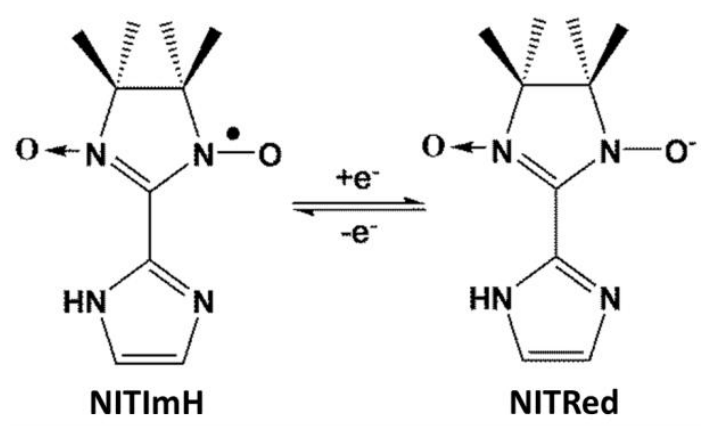

Scheme 2. Redox isomers for NITImH free radical.

With the aim of fully understanding the origin of such a dramatic change in magnetism, we report here an in-depth investigation of $\{[\mathrm{Mn} 2(\mathrm{NITIm}) 3] \mathrm{ClO} 4\} \mathrm{n}(1)$, combining a barrage of complementary techniques based on solid state temperature-dependent studies including crystal structure determination, magnetic susceptibility measurements, differential scanning calorimetry (DSC), electron paramagnetic resonance (EPR), UV-Vis spectroscopy, X-ray absorption (XAS) and emission (XES) spectroscopies of this 2D coordination polymer. The overall data can be rationalized by a solid state valence tautomerism in the room temperature domain. The transition is highly cooperative with a thermal hyste- 
resis, and is only observed in the solid state. Compound 1 represents the first example of a valence tautomerism transition involving nitronyl-nitroxide radicals, and the first example occurring in a Mn-based 2D coordination polymer.

\section{RESULTS AND DISCUSSION}

Magnetic behavior. Figure 1 shows the temperature dependent magnetic susceptibility measurements of 1 , in the form of $\chi \mathrm{T}$ vs. T under a magnetic field of $1000 \mathrm{Oe}$ and in the $375-2 \mathrm{~K}$ range upon cooling then heating. At $375 \mathrm{~K}$, the ? $\mathrm{T}$ value is $7.20 \mathrm{emu} \cdot \mathrm{K} \cdot \mathrm{mol}-1$. Upon cooling, ? $\mathrm{T}$ first increases to reach a maximum of $8.30 \mathrm{emu} \cdot \mathrm{K} \cdot \mathrm{mol}-1$ at $280 \mathrm{~K}$ then drops abruptly with an inflexion point at $274 \mathrm{~K}$ to reach a minimum of $5.81 \mathrm{emu} \cdot \mathrm{K} \cdot \mathrm{mol}-1$ at $250 \mathrm{~K}$. On further cooling, ? ? increases again to reach a maximum value of $8.23 \mathrm{emu} \cdot \mathrm{K} \cdot \mathrm{mol}-1$ at $5 \mathrm{~K}$. On heating the sample back, the ? ? vs. T curve is well superimposed on the cooling curve from $5 \mathrm{~K}$ to $250 \mathrm{~K}$. The heating curve keeps decreasing until $280 \mathrm{~K}$ where it abruptly increases to reach a value of $7.93 \mathrm{emu} \cdot \mathrm{K} \cdot \mathrm{mol}-1$ at $302 \mathrm{~K}$ with an inflexion point at $294 \mathrm{~K}$. The heating curve decreases to $\quad 7.26 \mathrm{emu} \cdot \mathrm{K} \cdot \mathrm{mol}-1$ at $375 \mathrm{~K}$, again superimposed to the cooling curve. This magnetic behavior is generally indicative of a first order phase transition with a hysteresis of $20 \mathrm{~K}$.

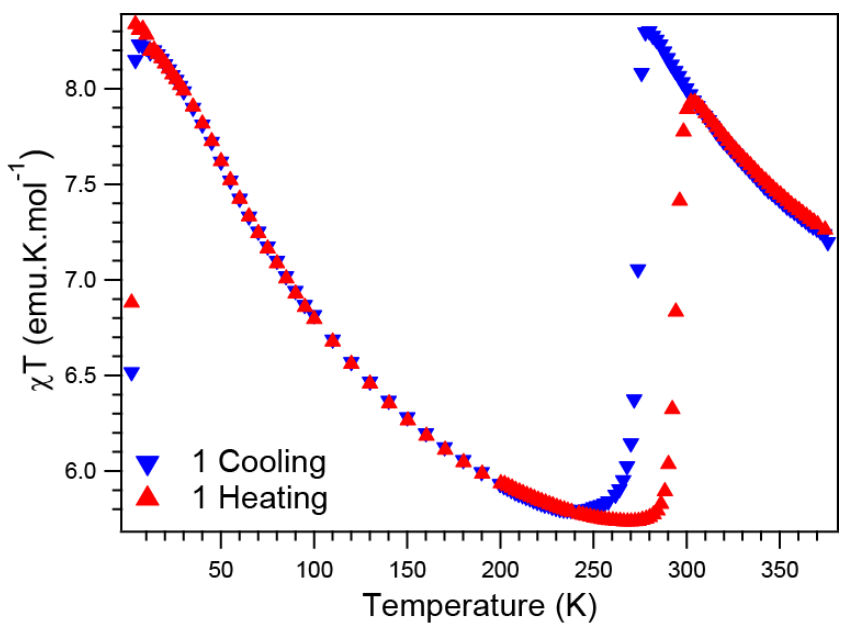

Figure 1. Temperature dependence of $\chi \mathrm{mT}$ for 1 , in a 1000 Oe magnetic field upon cooling $(\bullet)$ and heating $(\bullet)$.

The $1 / \chi$ vs. T curves on either side of the transition follow a Curie-Weiss law (Figure S1) with identical slopes corresponding to a Curie constant $(C)$ of $5.27 \mathrm{~cm} 3 \cdot \mathrm{K} \cdot \mathrm{mol}-1$, suggesting that the total spin of 1 at high temperature $(1 \mathrm{HT})$ is similar to the one at low temperature (1LT). The Weiss constants (?) are $100 \mathrm{~K}$ and $24 \mathrm{~K}$ for $1 \mathrm{HT}$ and $1 \mathrm{LT}$, respectively. This is in agreement with ferrimagnetic behaviors on both sides of the step, as previously reported for 1D and 2D $\mathrm{Mn}(\mathrm{II})-\mathrm{NITIm}$ and Mn(II)-NITBzIm compounds. $\underline{60}, \underline{68}$ This ferrimagnetic behavior is expected, at least for $1 \mathrm{HT}$, due to the strong antiferromagnetic coupling between the $\mathrm{Mn}(\mathrm{II})$ ions and the bridging radicals. $\underline{66}$ It is remarkable that the Curie (C) and Weiss (?) constants of $1 / \chi$ vs. T in the HT regime are close to those found for the 2D system with NITBzIm, that is, $\{[\mathrm{Mn} 2(\mathrm{NITBzIm}) 3] \mathrm{ClO} 4\} \mathrm{n}(\mathrm{C}=5.33 \mathrm{~cm} 3 \cdot \mathrm{K} \cdot \mathrm{mol}-1$, ? ? $]=105 \mathrm{~K})$. The same holds for the temperature dependence of ? (Figure S2). $\underline{68}$

Assuming that $1 \mathrm{HT}$ corresponds to [MnII2(NITIm)3ClO4]n, the total ground-state spin may be approximated to $\mathrm{S}=7 / 2$ (2]5/2 - 3]1/2) per unit formula. Because the Weiss constant dramatically decreases below the transition temperature, but the slopes do not change, this behavior was first ascribed to a weakening of the magnetic coupling between the $\mathrm{Mn}(\mathrm{II})$ ions and the bridging radicals at low temperature. This weakening could be due to some flexibility in the coordination sphere that results in a decrease in the overlap of the $\mathrm{Mn}(\mathrm{II})$ and radical magnetic orbitals. This explanation was supported by the fact that in the LT regime ? Moreover, ZFC-FC studies at low temperature evidence a remanent magnetization in agreement with a ferrimagnetic behavior below $1.4 \mathrm{~K} .67 \mathrm{In}$ Figure 1, the behavior of $1 \mathrm{LT}$ with its limiting ?T value of $8.23 \mathrm{emu} \cdot \mathrm{K} \cdot \mathrm{mol}-1$ at $5 \mathrm{~K}$ and gradual decrease to $5.81 \mathrm{emu} \cdot \mathrm{K} \cdot \mathrm{mol}-1$ is due to saturation effects under the magnetic field of 1000 Oe. Under a lower magnetic field (25 G), ? at $5 \mathrm{~T}$ with a value of $5.7 \mathrm{~B}$, which is well below the value of $7 \mu \mathrm{B}$ expected for $2 \mathrm{Mn}(\mathrm{II})$ antiferromagnetically coupled to 3 radicals (Figure S4). This low value could originate from canting, as also observed for the 2D system with NITBzIm $\{[\mathrm{Mn} 2(\mathrm{NITBz} / \mathrm{m}) 3] \mathrm{ClO} 4\}$ n. 68 However, investigating compound 1 in more detail with a set of different techniques, we have come to a better explanation, namely that the transition corresponds to valence tautomerism: two $\mathrm{Mn}$ (II) of $1 \mathrm{HT}$ are both oxidized to $\mathrm{Mn}(\mathrm{III})$ in $1 \mathrm{LT}$, while two among the three NITIm- radicals are reduced to their diamagnetic analogs so-called NITRed here (Scheme 2 ) to give the compound $\{[\mathrm{Mn} 2(\mathrm{NITIm})(\mathrm{NITRed}) 2] \mathrm{ClO} 4\}$. The resulting system can also be approximated to a total ground-state spin of $7 / 2$ in agreement with the identical slopes of the 1 /? ? vs. T plot on each side of the transition. The increase is thus explained by the delocalization of the radical. 
Differential Scanning Calorimetry. The DSC shows an exothermic peak at $274 \mathrm{~K}$ upon cooling and an endothermic peak at $287 \mathrm{~K}$ upon heating (Figure 2). The peak temperature on cooling is in agreement with the transition temperature found by the magnetic measurements (see above) and by absorption and EPR spectroscopies (see below), while the peak temperature on heating is lower by $7 \mathrm{~K}$. The enthalpy and entropy of the phase transition are ? $\mathrm{H}=12.54 \mathrm{~kJ} \cdot \mathrm{mol}-1$ and ? $\mathrm{S}=45.75 \mathrm{~J} \cdot \mathrm{K}-1 \cdot \mathrm{mol}-1$ upon cooling and ? $\mathrm{H}=-12.08 \mathrm{~kJ} \cdot \mathrm{mol}-1$ and $\Delta \mathrm{S}=-42.08 \mathrm{~J} \cdot \mathrm{K}-1 \cdot \mathrm{mol}-1$ upon heating. The heat capacity measured by DSC with the $\mathrm{Cp}$ of sapphire as reference (Figure S5) decreases smoothly upon cooling with a broad peak at $274 \mathrm{~K}$ and increases continuously on heating with a broad peak at 287K. We further performed modulated-temperature DSC measurements (Figures S6-S7). $\underline{69}$ Whether upon cooling or heating, they both exhibit the reversing and the non-reversing components which respectively discriminate the sensible and the latent heats, and unambiguously demonstrates that the transition is of the first order type. 70,71 More surprisingly, we found that the nonreversing peak (latent heat) splits at low heating rate. Thus at $2 \mathrm{~K} \cdot \mathrm{min}-1$ (Figure S7) there are a main broad peak at 285 $\mathrm{K}$ and a second broad flattening peak centred at $300 \mathrm{~K}$, which roughly correspond to the beginning and the end of transition, as seen on heating from the magnetic measurement (Figure 1). This effect is not seen upon cooling. Such a splitting and dependence on heating rate is reminiscent of some previous studies on solids exhibiting transition upon disproportionation. $\underline{71-73}$

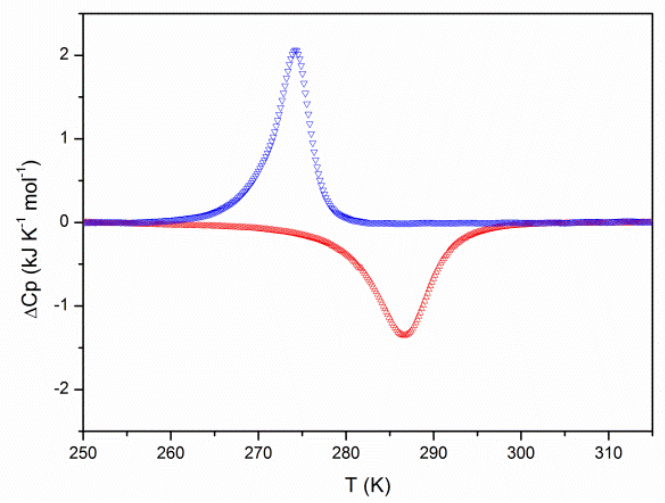

Figure 2. Differential scanning calorimetry (DSC) for 1 upon cooling ( $\boldsymbol{\nabla})$ and heating $(\boldsymbol{\Delta})$ at $10 \mathrm{~K} \cdot \mathrm{min}-1$.

We believe this may be paralleled with the valence tautomerism at work in our compound. Following we ascribe the two latent heat peaks (285K and $300 \mathrm{~K}$ ) to the non-simultaneity of the electron transfer involving the two crystallographically independent manganese ions.

X-ray single crystal structure analysis. The crystal structure of 1 has been reported previously at $313 \mathrm{~K}(1 \mathrm{HT})$ and $193 \mathrm{~K}$ (1LT). 67 X-ray data have also been recorded at $300 \mathrm{~K}$ and $233 \mathrm{~K}$, in order to get additional insight into the temperaturedependency of the structural properties of 1 . At all temperatures the structure could be refined in the same space group, namely P21, indicating that no structural phase transition occurs. The crystal structure parameters are listed in Tables 1 and S1-S3. The variation of all parameters is less than $4 \%$. The evolution of metal-ligand bond lengths varies from bond to bond (Table S2). The room temperature X-ray powder pattern is similar to the calculated ones at $313 \mathrm{~K}$ and $300 \mathrm{~K}$, with significant changes compared to calculated ones at $233 \mathrm{~K}$ and $193 \mathrm{~K}$ (Figure S8).

The crystal structure determination of 1 at $300 \mathrm{~K}$ confirms the previously reported structure at $313 \mathrm{~K} . \underline{67}$ The asymmetric unit is composed of two independent Mn centers, coordinated to three bidentate NITIm- anion radicals in a distorted octahedral geometry (Figure S9). The alternating ? and ? coordination isomers lead to the formation of a 2D honeycomb-like structure, organized as sheets of formula [Mn2(NITIm)3]+. The sheets are arranged with the Mn(II) centers on top of each other along the a direction and with the $\mathrm{ClO} 4$ - anions in the voids between the sheets to form a layered structure (Figures 3 and S5-S6).

When decreasing the temperature, the overall layered structure is kept in line with the unchanged space group. However, examination of the coordination sphere reveals dramatic changes as shown in Table 2. At $313 \mathrm{~K}$, the $\mathrm{Mn}-\mathrm{O}$ and Mn-N bond lengths are homogenous between 2.16- $2.23 \AA$ with a small shortening at $300 \mathrm{~K}$, which can be ascribed to temperature effects. These bond lengths are typical for $\mathrm{Mn}(\mathrm{II})$ coordination with $\mathrm{N}$ - and O-based ligands, particularly with $\mathrm{Mn}$-nitroxide compounds. $\underline{60}, \underline{66}$

At $233 \mathrm{~K}$ and $193 \mathrm{~K}$ the picture is notably different. The range of $\mathrm{Mn}-\mathrm{O}$ and $\mathrm{Mn}-\mathrm{N}$ bond lengths is no longer homogenous, with values ranging from 1.83-2.24 $\AA$ at $233 \mathrm{~K}$ and $1.85-2.27 \AA$ at $193 \mathrm{~K}$, with four long and two short bonds. On the one hand, the short distances (1.83 $\AA$ and $1.85 \AA$ ) are unrealistic for $\mathrm{Mn}(\mathrm{II})$. On the other hand, the overall contraction along one preferential axis is the signature of a compressed Jahn-Teller Mn(III) system. $\underline{74-76}$ 

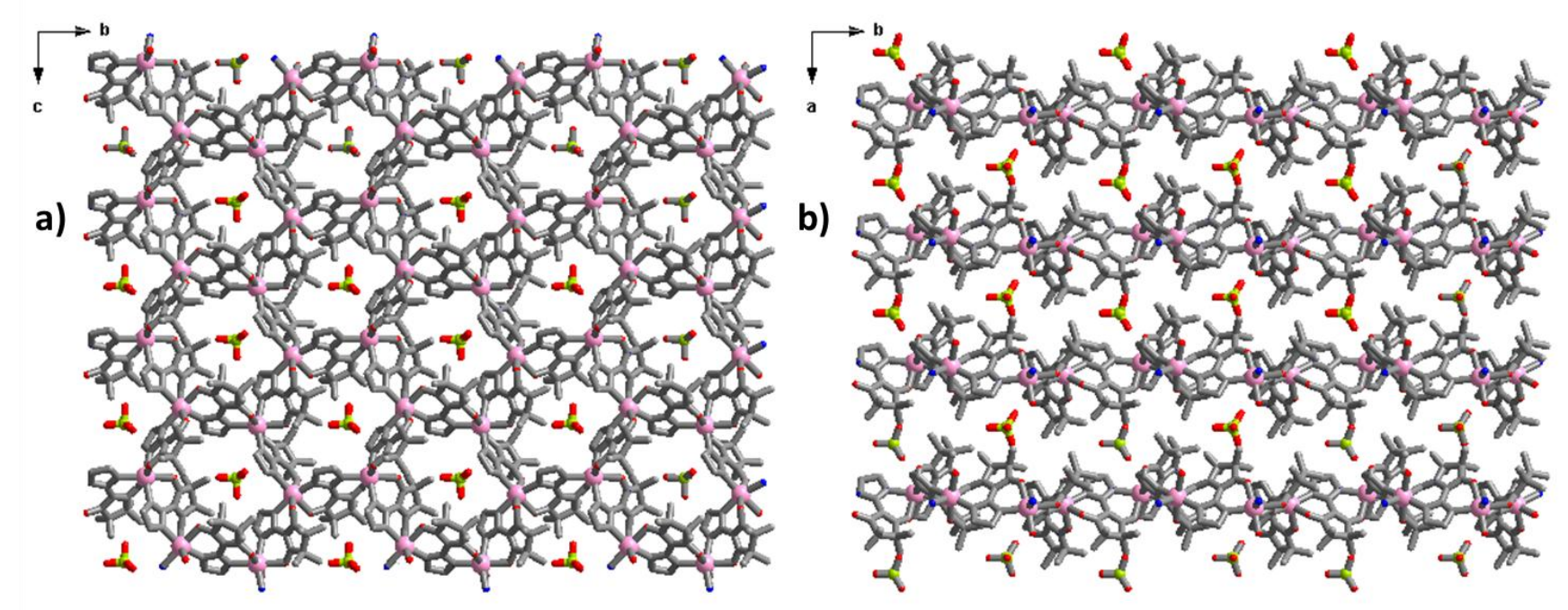

Figure 3. a) Crystal packing in the bc plane showing bidimensional honeycomb-like structure at $300 \mathrm{~K}$. b) Crystal packing in the ab plane showing layers piling up along a axis and interlayer space filled with $\mathrm{ClO} 4$ - anion at $300 \mathrm{~K}$. Hydrogen atoms have been removed for clarity.

Table 1. Crystal data of 1 at several different temperatures.

\begin{tabular}{|c|c|c|c|c|c|}
\hline Formula & \multicolumn{4}{|c|}{$\mathrm{Mn} 2 \mathrm{C} 30 \mathrm{H} 42 \mathrm{ClN} 12 \mathrm{O} 10$} & Variation (\%) 313-193 K \\
\hline $\mathrm{M}(\mathrm{g} / \mathrm{mol})$ & \multicolumn{4}{|l|}{876.09} & ---- \\
\hline Crystal system & \multicolumn{4}{|l|}{ Monoclinic } & ---- \\
\hline Space group & \multicolumn{4}{|l|}{ P21 } & ---- \\
\hline Temperature (K) & $313(2)$ & $300(2)$ & $233(2)$ & $193(2)$ & ---- \\
\hline a $(\AA ̊)$ & $10.325(1)$ & $10.307(1)$ & $10.597(4)$ & $10.688(3)$ & +3.5 \\
\hline$b(\AA)$ & $17.870(1)$ & $17.861(2)$ & $17.037(7)$ & $17.165(5)$ & -3.9 \\
\hline$c(\AA)$ & $11.063(1)$ & $11.019(1)$ & $10.657(5)$ & $10.761(4)$ & -2.7 \\
\hline$\beta\left(^{\circ}\right)$ & $93.430(4)$ & $93.638(2)$ & $90.623(8)$ & $90.648(6)$ & -3.0 \\
\hline V (Å3) & $2037.5(3)$ & $2024.5(4)$ & 1924.0(1) & 1974.1(1) & -3.1 \\
\hline
\end{tabular}

This is substantiated by the Bond Valence Sums calculated for each manganese ion at each temperature (Table S2).77They reveal that both manganese ions are closer to the +1 oxidation state at temperatures above the transition ( $313 \mathrm{~K}$ and $300 \mathrm{~K})$, and closer to the +III oxidation state at lower temperatures (233 K and $193 \mathrm{~K}$ ).

The N-O bond lengths of the NITIm- moiety are summarized at each temperature in Table S3. On the one hand, those usually encountered in NIT radicals coordinated to a manganese ion are in the 1.27-1.33 $\AA$ range, regardless of the oxidation state.78-82 On the other hand, the $\mathrm{N}-\mathrm{O}$ - single bond is close to $1.40 \AA$, while the $\mathrm{N}=\mathrm{O}$ double bond is close to $1.21 \AA .83$ For 1 , at $313 \mathrm{~K}$, the $\mathrm{N}-\mathrm{O}$ bond lengths are quite homogenous with a mean value of $1.29 \AA$ (2) well in agreement with a nitroxide radical. At lower temperatures and particularly at $233 \mathrm{~K}$ and $193 \mathrm{~K}$, the $\mathrm{N}-\mathrm{O}$ bonds length show a higher spreading with some close to $1.40 \AA$ consistent with $\mathrm{N}-\mathrm{O}$ - single bonds. A quick view of the $\mathrm{N}-\mathrm{O}$ distances may suggest that only two radicals (namely $A$ and $C$ ) are affected by the elongation of bond lengths while the third one (namely B) displays classical $\mathrm{N}-\mathrm{O} \bullet$ bonds over the temperature range in agreement with our above description of VT process in 1. However, a close analysis shows that it is difficult to unambiguously identify which radicals are reduced or not, as short and long bonds are found on a same "NITIm" moiety and the N-O mean bond length is $1.33(3) \AA$, even at $193 \mathrm{~K}$. This suggests that in the low temperature region the remaining radical is delocalized on the three "NITIm" moieties. Such a delocalized mixed valence state for the radical is in agreement with the long range magnetic order observed at low temperature. Moreover, the Jahn-Teller distortion of the $\mathrm{Mn}$ (III) metal ions may be the cause of the $20 \mathrm{~K}$ width hysteresis loop because it is known to stress cooperative effects in different class of compounds such as the closely related spin crossover systems. $\underline{\mathbf{8 4}-86}$ 
Table 2. Mn-Ligand Bond lengths for 1 at several temperatures.

\begin{tabular}{|c|c|c|c|c|c|}
\hline \multicolumn{2}{|c|}{ Bonds (Å) } & \multirow{2}{*}{$\frac{313 \mathrm{~K}}{2.22(2)}$} & \multirow{2}{*}{$\frac{300 \mathrm{~K}}{2.19(3)}$} & \multirow{2}{*}{$\frac{233 \mathrm{~K}}{2.19(3)}$} & \multirow{2}{*}{$\frac{193 \mathrm{~K}}{2.15(3)}$} \\
\hline Mn1 & N3A & & & & \\
\hline Mn1 & N3B & $2.26(2)$ & $2.24(2)$ & $2.10(3)$ & $2.07(2)$ \\
\hline Mn1 & N3C & $2.11(3)$ & $2.14(2)$ & $2.11(3)$ & $2.07(3)$ \\
\hline Mn1 & O1A & $2.18(2)$ & $2.18(2)$ & $1.93(3)$ & $1.90(3)$ \\
\hline Mn1 & O1B & $2.29(2)$ & $2.28(2)$ & $2.26(3)$ & $2.27(2)$ \\
\hline Mn1 & O1C & $2.16(2)$ & $2.07(2)$ & $1.83(3)$ & $1.95(2)$ \\
\hline Mn2 & N4A & $2.17(2)$ & $2.08(2)$ & $2.06(4)$ & $2.08(3)$ \\
\hline Mn2 & N4B & $2.17(3)$ & $2.14(2)$ & $1.95(4)$ & $2.07(3)$ \\
\hline Mn2 & $\mathrm{N} 4 \mathrm{C}$ & $2.20(2)$ & $2.19(2)$ & $1.94(3)$ & $1.99(3)$ \\
\hline Mn2 & $\mathrm{O} 2 \mathrm{~A}$ & $2.19(2)$ & $2.15(2)$ & $1.89(3)$ & $1.85(2)$ \\
\hline Mn2 & O2B & $2.20(2)$ & $2.16(2)$ & $2.24(2)$ & $2.22(2)$ \\
\hline Mn2 & $\mathrm{O} 2 \mathrm{C}$ & $2.23(2)$ & $2.18(2)$ & $2.05(2)$ & $2.04(2)$ \\
\hline
\end{tabular}

UV-vis spectroscopy. To confirm the aforementioned hypothesis, temperature-dependent solid-state UV-Vis spectra were carried out. Figure 4 shows the absorption spectra in heating mode (Figure S10 for cooling mode). At $310 \mathrm{~K}$ the spectrum shows a broad and intense band with two maxima in the range 35000-23500 cm-1 (290-425 nm), corresponding to $\pi \rightarrow \pi^{*}$ and $n \rightarrow \pi^{*}$ transitions from the NITIm- ligands, respectively. Another broad band centered at $12660 \mathrm{~cm}-1(790 \mathrm{~nm})$ is visible at $310 \mathrm{~K}$.

On cooling from 310 to $250 \mathrm{~K}$, the maximum of this band slightly shifts to the blue, concomitant with a decrease of the integrated intensity by around $50 \%$. The bands in the 35000 to $23500 \mathrm{~cm}-1$ range likewise decrease in intensity. Concomitantly, a new band appears in the range 23500 to $15400 \mathrm{~cm}-1(425-650 \mathrm{~nm})$ and its intensity increases as temperature decreases. Upon subsequent heating from $250 \mathrm{~K}$ back to $310 \mathrm{~K}$ the evolution of the absorption spectrum is fully reversible. The temperature-dependent quantitative evolution of the absorbance at $510 \mathrm{~nm}$, where the most pronounced difference occurs, is depicted in Figure 5 in the interval from $250 \mathrm{~K}$ to $310 \mathrm{~K}$.

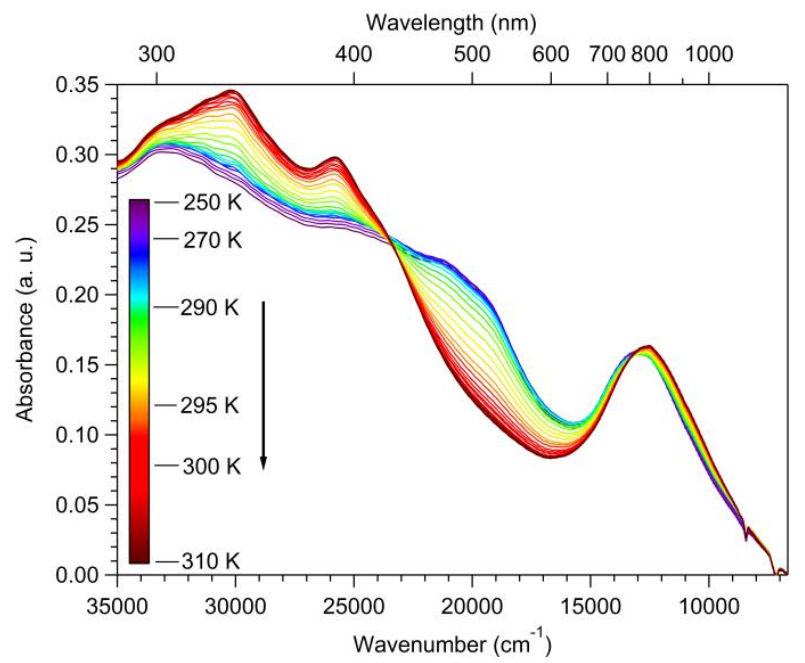

Figure 4. Temperature dependence of the solid-state absorption spectra for 1 during heating. Temperature rate was monitored at $0.25 \mathrm{~K} \cdot \mathrm{min}-1$.

It shows that the optical and magnetic data, on cooling and on heating, are perfectly superimposable, reproducing the $20 \mathrm{~K}$ hysteresis. Thus the changes in the absorption spectrum as a function of temperature are clearly associated with the phase transition and show that the associated changes in the electronic structure are quite dramatic. 


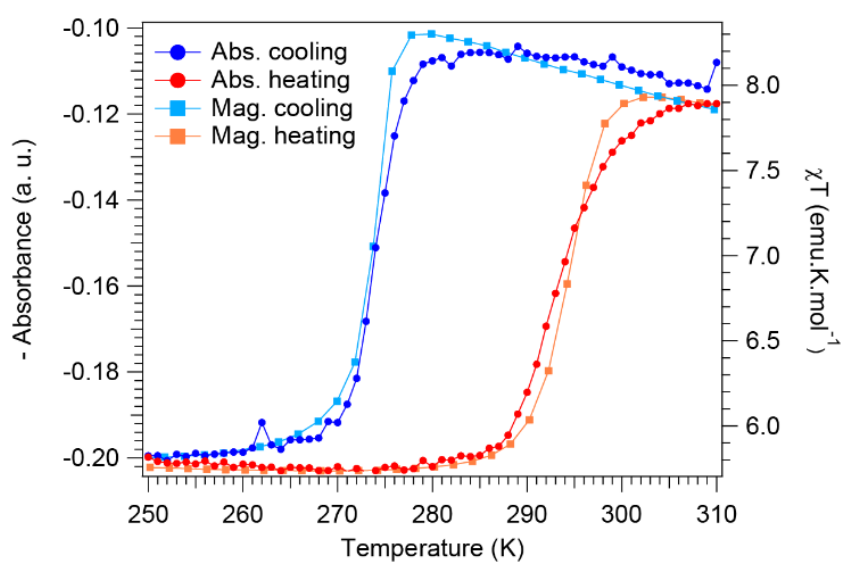

Figure 5. Superimposition of $510 \mathrm{~nm}$ absorption (circles) with magnetic susceptibility (squares) during cooling (blue) and heating (red). Lines are eye-guides.

Raman. Variable-temperature Raman spectra at three excitation wavelengths are shown in Figure 6. Intensities of Raman peaks reflect the absorption changes in Figure 4 . At $514 \mathrm{~nm}$, very near to the absorption band maxima reflecting the VT transition, the most intense Raman signals are observed at approximatively $1600 \mathrm{~cm}-1$ and are clearly resonance enhanced. While at room temperature, the most intense feature is at $1564 \mathrm{~cm}-1$, a shoulder remains at low temperature at this wavelength, with two maxima at $1598 \mathrm{~cm}-1$ and $1620 \mathrm{~cm}-1$. This shift reflects the VT transition, as no such shift is observed in the progression intervals of nitronyl nitroxide complexes without VT transitions. 87 At 633 $\mathrm{nm}$, the same change of Raman shifts is observed for the corresponding signals. In contrast, the intensity of the signals is no longer higher than for the other Raman peaks, illustrating the resonance enhancement at $514 \mathrm{~nm}$. At $785 \mathrm{~nm}$, the signals at $1600 \mathrm{~cm}-1$ are much weaker than the other Raman transitions, indicating the absence of resonance excitation. Differences in $\mathrm{N}-\mathrm{O}$ bond lengths between the nitroxide and the aminoxyl forms should result in different Raman shifts. The N-O e stretching frequency for NITs is approximately at 1350-1400 cm-1. $\underline{88}, \underline{89}$ The Raman spectra excited at $633 \mathrm{~nm}$ and $785 \mathrm{~nm}$ show clear peaks in this region. The most intense peak of this group shifts from $1417 \mathrm{~cm}-1 \mathrm{at}$ room temperature to $1421 \mathrm{~cm}-1$ at low temperature (Figure S11). Such small changes cannot be unambiguously attributed to VT transition as all frequencies are expected to increase at low temperature. $\underline{90}$

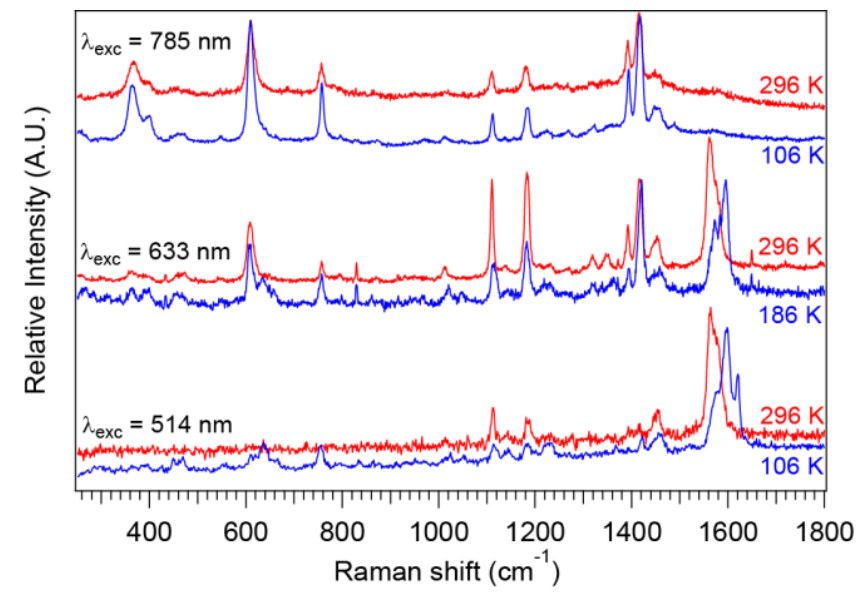

Figure 6. Variable-temperature Raman spectra of 1 at three excitation wavelengths.

EPR spectroscopy: Powder X-band EPR spectra of [Mn2(NITIm)3ClO4]n 1 have been recorded between 310 and 110 K, and displays a unique isotropic feature centered around $\mathrm{g}=2$ (Figure 7a). Unexpectedly, the signal intensity decreases as temperature decreases. A drastic decrease of the intensity is observed on cooling around $276 \mathrm{~K}$, while the drastic increase occurs around $296 \mathrm{~K}$ on heating. This temperature behavior parallels that of the magnetic susceptibility and solid-state absorption spectroscopy, evidencing that the isotropic EPR signal is the signature of 1 at high temperature. The $20 \mathrm{~K}$ hysteresis can be reproduces with a double integration of the EPR signal (Figure 7b). Interestingly, at low temperature and in parallel mode X-band EPR, a low-field EPR signal is observed, characteristic of high spin Mn(III) (Figure 8).91, 92 This is consistent with the fact that below the transition temperature, the oxidation state of the Mn ions can be assigned to +III. EPR is thus in overall agreement with the other data, and provides a direct evidence of the Mn oxidation state in 1LT. 

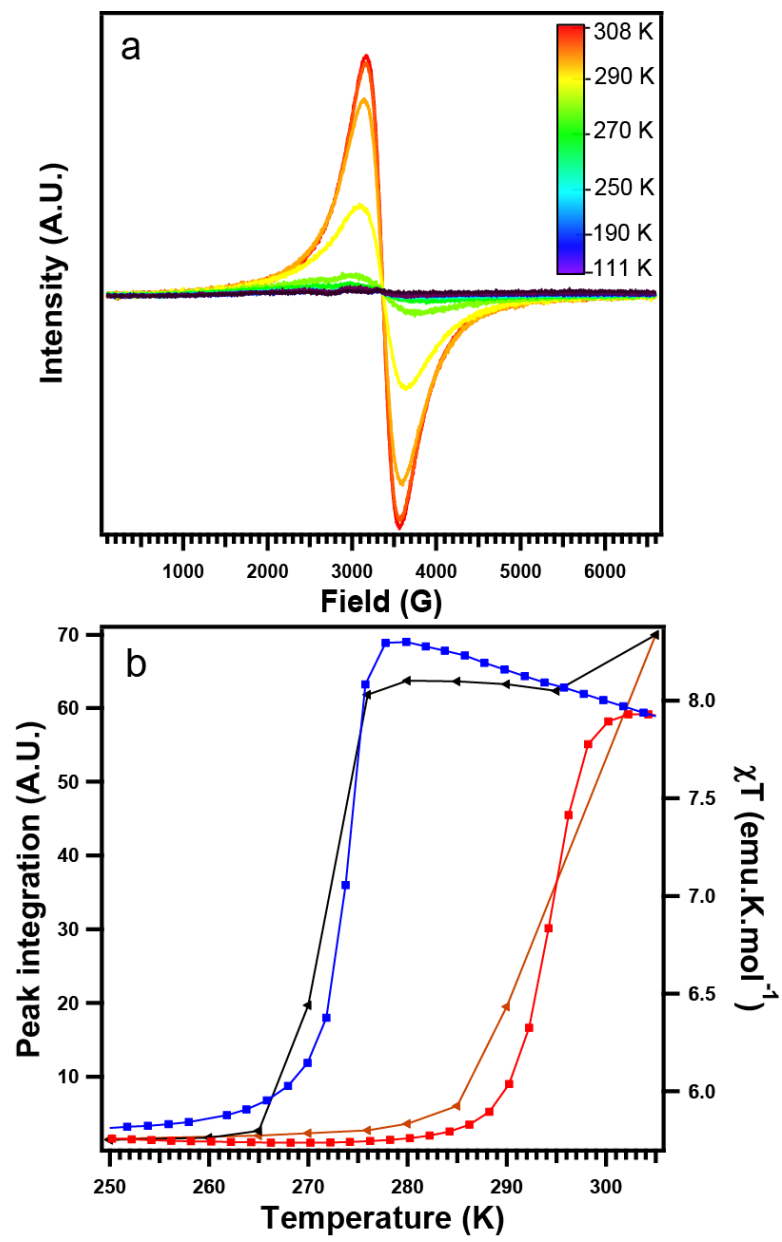

Figure 7. (a) Temperature dependence of the solid-state X-band EPR spectra for 1 during heating. (b) Superimposition of the magnetic data (square) and the intensity of the EPR lines (triangle) during cooling (blue shades) and heating (red shades). Lines are eye-guides.

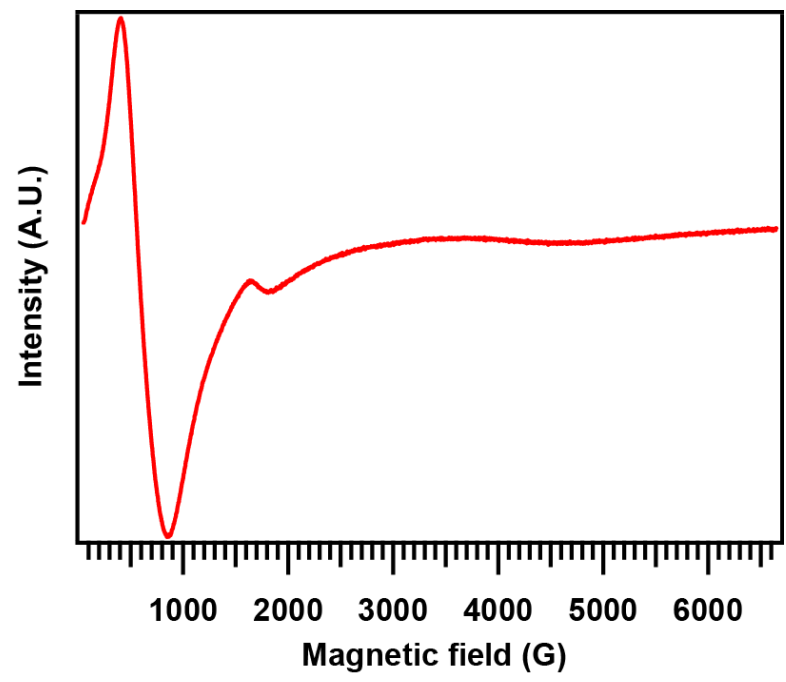

Figure 8. Powder X-band EPR spectrum of 1 recorded at $21 \mathrm{~K}$ in parallel mode.

Mn K edge X-ray emission spectroscopy (XES). XES and XAS measurements have been carried out on the CRG-FAME beamline (BM30B) at the ESRF (Grenoble, France). 93 XES spectra were recorded at $300 \mathrm{~K}$ and $10 \mathrm{~K}$ for 1 and for two $\mathrm{Mn}(\mathrm{II})$ and $\mathrm{Mn}(\mathrm{III})$ reference compounds (Figure 9). The $\mathrm{Mn}(\mathrm{II})$ reference corresponds to the 2D $\{[\mathrm{Mn} 2(\mathrm{NITBzIm}) 3] \mathrm{ClO} 4\} \mathrm{n}$ compound and the $\mathrm{Mn}(\mathrm{III})$ reference corresponds to a $[\mathrm{Mn}(\mathrm{ImIm}) 2(\mathrm{CH} 3 \mathrm{OH}) 2] \mathrm{ClO} 4$ isolated complex (ImIm- = 2-(2-imidazolyl)-4,4,5,5-tetramethyl-4,5-dihydro-1H-1-oxyl). 


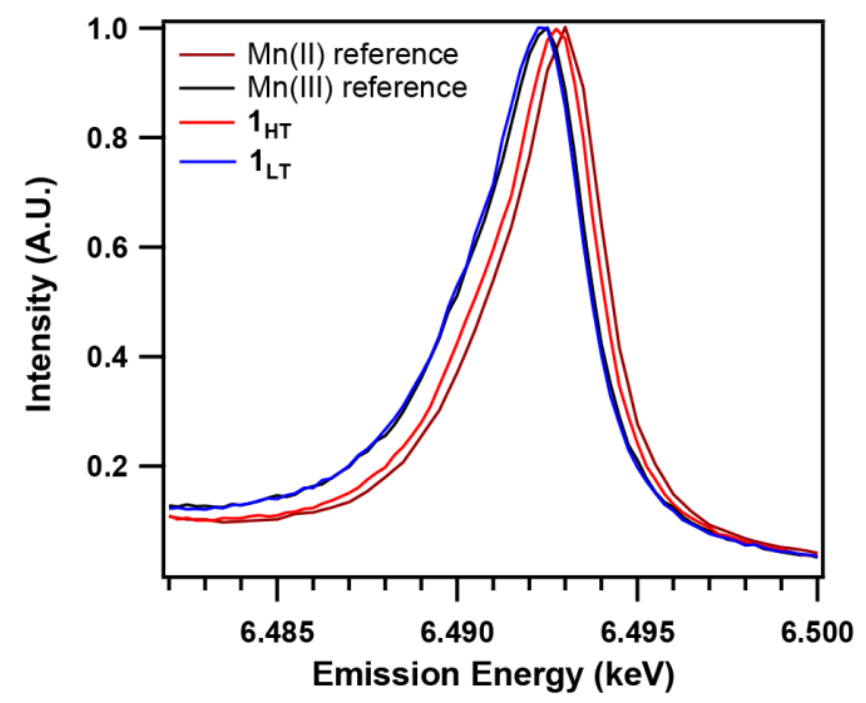

Figure 9. X-ray Emission Spectra (XES) for 1 collected at high and low temperatures for comparison with the $\mathrm{Mn}(\mathrm{II})$ and $\mathrm{Mn}(\mathrm{III})$ references.

At $300 \mathrm{~K}$ the emission data show that the spectrum of $1 \mathrm{HT}$ is superimposed with the spectrum of the Mn(II) reference68 while at $10 \mathrm{~K}$ the spectrum of $1 \mathrm{LT}$ is very similar to the one of the $\mathrm{Mn}(\mathrm{III})$ reference. Intensity ratios are identical. $\mathrm{K} \beta$ line positions are at $6.4775 \mathrm{keV}$ for the references and for $1 \mathrm{HT}$ and $1 \mathrm{LT}$.

$\mathrm{K} \beta 1,3$ maximum is at $6.4230 \mathrm{keV}$ for $\mathrm{Mn}(\mathrm{II})$ reference and $1 \mathrm{HT}$ at $300 \mathrm{~K}$ and is shifted towards the low energies by 0.5 $\mathrm{eV}$ at $6.4225 \mathrm{keV}$ for $\mathrm{Mn}(\mathrm{III})$ reference and $1 \mathrm{LT}$ at $10 \mathrm{~K}$. This is a good indication for the presence of $\mathrm{Mn}(\mathrm{II})$ at $\mathrm{HT}$ and $\mathrm{Mn}(\mathrm{III})$ at LT, consistent with the VT transition.

Mn K edge X-ray absorption spectroscopy (XAS). The XANES spectra (Figure 10a) can give information on the Mn valence through two characteristic features: the pre-edge signal and the edge position. At $300 \mathrm{~K}$, the pre-edge signal of $1 \mathrm{HT}$ has the same shape and position as the pre-edge signal of the $\mathrm{Mn}$ (II) reference (6.5405 keV), irrespective of whether the spectrum of $1 \mathrm{HT}$ is collected at the $\mathrm{Mn}$ (II) or $\mathrm{Mn}(\mathrm{III})$ maximum energy emission, showing that the precise energy of collection has no influence on the final result (Figure 10b). The edge positions of $1 \mathrm{HT}$ and of the $\mathrm{Mn}$ (II) reference is at the same energy $(6.546 \mathrm{keV})$, confirming the + Il oxidation state for $1 \mathrm{HT}$ (Figure 10c). At $10 \mathrm{~K}$, the pre-edge signal of $1 \mathrm{LT}$ has the same shape and position as the pre-edge signal of the $\mathrm{Mn}(\mathrm{III})$ reference and is at the same energy as the HT spectrum (6.5405 keV), but the intensity is lower. Compared to the $\mathrm{Mn}$ (II) reference, the edge positions of the $\mathrm{Mn}(\mathrm{III})$ reference and $1 \mathrm{LT}$ collected at the $\mathrm{Mn}(\mathrm{III})$ maximum energy emission are shifted toward higher energy by ca. $2.5 \mathrm{eV}$ at $6.5485 \mathrm{keV}$. This indicates a transition from $\mathrm{Mn}(\mathrm{II})$ to $\mathrm{Mn}$ (III) at low temperature.

1LT evolves under the beam, and the edge position is shifted towards lower energies $(0.1 \mathrm{eV} \cdot \mathrm{h}-1)$. Thus, only the first spectrum is presented here, explaining the poorer statistics compared to the five other spectra. The difference of $1 \mathrm{eV}$ between the 1 LT spectra, collected at the $\mathrm{Mn}$ (III) emission maximum and at the $\mathrm{Mn}$ (II) emission maximum, is mainly due to this evolution under the beam, since the latter was collected at the end of the experiment. Nevertheless, the spectra confirm the consistency of the results whatever the energy of collection. 

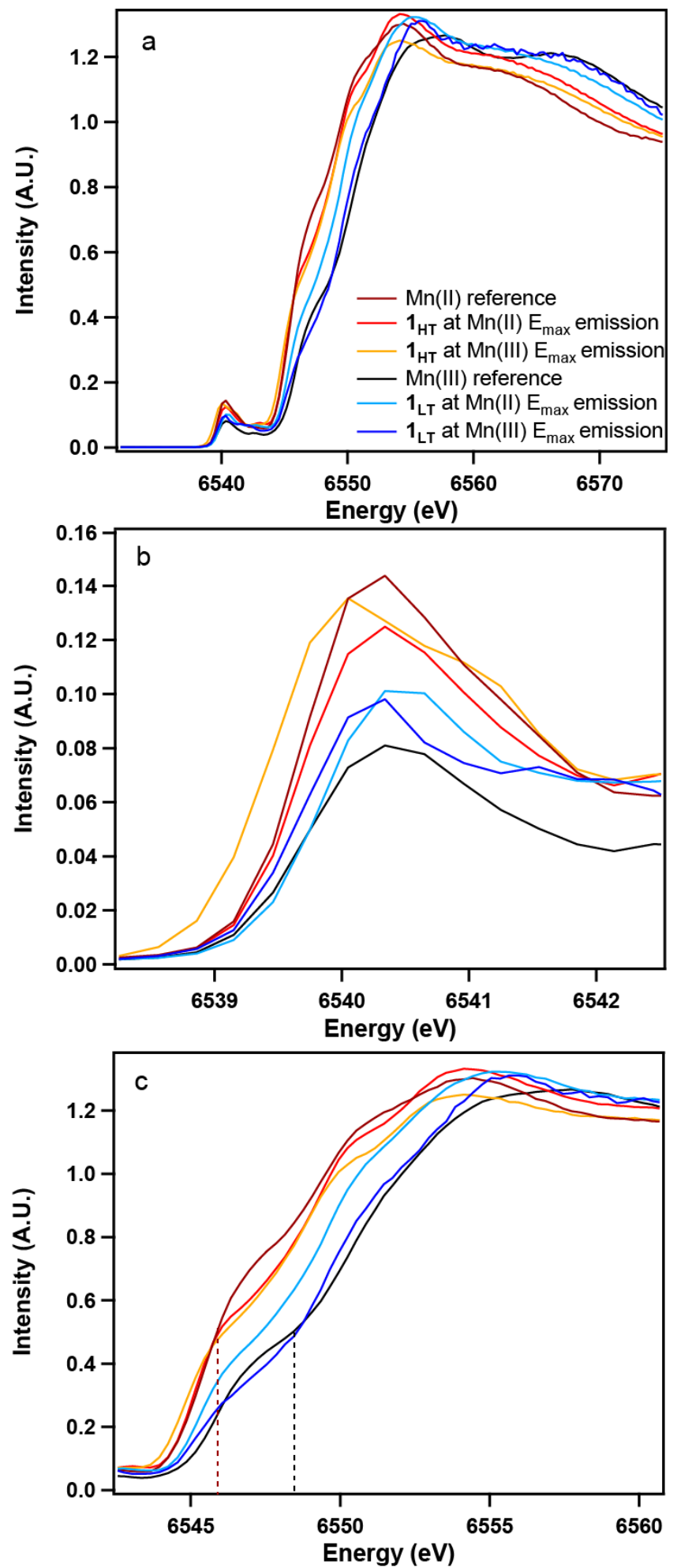

Figure 10. a) XANES Spectra (XES) for 1 collected at high and low temperatures with the Mn(II) and Mn(III) references. b) Zoom on the pre-edge signal area. c) Zoom on the edge position area. Brown and black dotted lines are maximum intensity for the $\mathrm{Mn}(\mathrm{II})$ and $\mathrm{Mn}(\mathrm{III})$ references, respectively. 


\section{CONCLUSION}

In this paper we report the detailed solid-state study of the thermo-induced hysteretic transition exhibited by the 2D coordination polymer $\{[\mathrm{Mn} 2(\mathrm{NITIm}) 3] \mathrm{ClO} 4\} \mathrm{n}$. Temperature-dependent studies using a variety of techniques including single crystal X-ray crystallography, magnetic susceptibility measurements, DSC, EPR, UV-vis absorption spectroscopy, XAS and XES have been performed and all demonstrate that this thermo-induced transition is unambiguously due to a valence tautomerism process. Along this VT process the two manganese ions in their +ll oxidation state at high temperature are oxidized to the +III oxidation state at low temperature and two of the three NITImH radicals are reduced to the NITRed aminoxyl and diamagnetic anion (Scheme 2). From electrochemistry experiments (Supporting Information) and in agreement with previous reports $\underline{94}$ the $\mathrm{E} 1 / 2$ redox potential aminoxyl anion/nitroxide radical, is $0.25 \mathrm{~V} / \mathrm{SHE}$ (Standard Hydrogen Electrode) as shown in Figure S12 while the redox potential of the system Mn3+/Mn2+ is given higher at $1.54 \mathrm{~V} / \mathrm{SHE}$. This is in favor for stable Mnll-nitroxide complexes as it is generally observed. Thus, the simple comparison of the redox potential cannot explain this thermo-induced VT. This may be due that the redox potential are determinate in solution while VT happens here in the solid state. Multiscale quantum calculations that are in progress should give a better view.

To the best of our knowledge this is the first metal-nitroxide radical system to exhibit bistability based on valencetautomerism. Moreover, this is associated with a $20 \mathrm{~K}$ hysteresis at room temperature. This opens novel perspectives for the so called metal-radical approach. Indeed, beyond the interest of nitronyl-nitroxide radicals as spin-carriers bridging ligands, this result shows that their redox activity can give rise in some cases to metal-radical electron transfer. This may be an additional advantage in the context of multifunctional materials, especially in the search for switchable magnets. The compound reported here is based on layered 2D metal-radical coordination polymer. It is noteworthy that the [Mn2(NITIm)3]+ layers are cationic with the intercalated perchlorate anions in between, to afford a layered 3D chiral structure. From this point of view, it is a multifunctional material that gathers many interesting functionalities such as room temperature bistability, ferrimagnetic behavior and chirality. The synthesis is general and may be extended to the related imidazole type substituted nitronyl-nitroxide radical while almost any type of anions can be intercalated. This allows a great versatility to tune the temperature of the transition or implement the multifunctionality, and accordingly work is in progress in the group.

\section{ASSOCIATED CONTENT}

Experimental details, complete crystallographic data and figures giving additional data. This material is available free of charge via the internet at http://pubs.acs.org.

\section{AUTHOR INFORMATION \\ Corresponding Author \\ * Corresponding authors: dominique.luneau@univ-lyon1.fr.}

\section{Notes}

Authors declare no competing financial interests.

\section{ACKNOWLEDGMENTS}

A.L. held a CMIRA Explora' doc 2012 fellowship from la Région Rhône-Alpes. D.L. and C.R. are grateful for funding by the Centre National de la Recherche Scientifique (CNRS) for collaborative research (PICS 2015-2017). The authors are also grateful to the EPR facilities available at the national EPR network (IT CNRS 3443).

\section{REFERENCES}

(1) Gutlich, P.; Hauser, A.; Spiering, H. Angew. Chem. Int. Ed. 1994, 33, 2024.

(2) Irie, M. Chem. Rev. 2000, 100, 1685.

(3) Balzani, V.; Credi, A.; Langford, S. J.; Raymo, F. M.; Stoddart, J. F.; Venturi, M. J. Am. Chem. Soc. 2000, 122, 3542.

(4) Gütlich, P.; Garcia, Y.; Woike, T. Coord. Chem. Rev. 2001, 219-221, 839.

(5) Schaniel, D.; Imlau, M.; Weisemoeller, T.; Woike, T.; Kraemer, K. W.; Guedel, H.-U. Adv. Mater. 2007, 19, 723.

(6) Sato, O.; Tao, J.; Zhang, Y. Z. Angew. Chem. Int. Ed. 2007, 46, 2152.

(7) Munoz, M. C.; Real, J. A. Coord. Chem. Rev. 2011, 255, 2068.

(8) Manrique-Juarez, M. D.; Rat, S.; Salmon, L.; Molnar, G.; Quintero, C. M.; Nicu, L.; Shepherd, H. J.; Bousseksou, A. Coord. Chem. Rev. 2016, 308, 395.

(9) Hendrickson, D. N.; Pierpont, C. G. Top. Curr. Chem. 2004, 234, 63. 
(10) Pierpont, C. G. Coord. Chem. Rev. 2001, 219-221, 415.

(11) Tezgerevska, T.; Alley, K. G.; Boskovic, C. Coord. Chem. Rev. 2014, 268, 23.

(12) Buchanan, R. M.; Pierpont, C. G. J. Am. Chem. Soc. 1980, 102, 4951.

(13) Adams, D. M.; Li, B.; Simon, J. D.; Hendrickson, D. N. Angew. Chem. Int. Ed. 1995, 34, 1481.

(14) Attia, A. S.; Junga, O.-S.; Pierpont, C. G. Inorg. Chim. Acta 1994, 226, 91.

(15) Carbonera, C.; Dei, A.; Létard, J.-F.; Sangregorio, C.; Sorace, L. Angew. Chem. Int. Ed. 2004, 43, 3136.

(16) Cui, A.; Takahashi, K.; Fujishima, A.; Sato, O. J. Photochem. Photobiol., A 2004, 167, 69.

(17) Cui, A.; Takahashi, K.; Fujishima, A.; Sato, O. J. Photochem. Photobiol., A 2004, 161, 243.

(18) G. A. Abakumov, V. K. C., M. P. Bubnov, O. G. Ellert, Z. V. Dobrokhotova, L. N. Zakharov, Yu. T. Struchkov Dokl. Akad. Nauk SSSR 1993, 328, 332.

(19) Jung, O.-S.; Jo, D. H.; Lee, Y.-A.; Conklin, B. J.; Pierpont, C. G. Inorg. Chem. 1997, 36, 19.

(20) Jung, O.-S.; Jo, D. H.; Lee, Y.-A.; Sohn, Y. S.; Pierpont, C. G. Inorg. Chem. 1998, 37, 5875.

(21) Katayama, K.; Hirotsu, M.; Kinoshita, I.; Teki, Y. Dalton Trans. 2014, 43, 13384.

(22) Maity, S.; Kundu, S.; Bera, S.; Weyhermüller, T.; Ghosh, P. Eur. J. Inorg. Chem. 2016, 3680.

(23) Minkin, V. I.; Starikova, A. A.; Starikov, A. G. Dalton Trans. 2015, 44, 1982.

(24) Poneti, G.; Mannini, M.; Sorace, L.; Sainctavit, P.; Arrio, M.-A.; Otero, E.; Criginski Cezar, J.; Dei, A. Angew. Chem. Int. Ed. 2010, 49, 1954.

(25) Tao, J.; Maruyama, H.; Sato, O. J. Am. Chem. Soc. 2006, 128, 1790.

(26) Witt, A.; Heinemann, F. W.; Sproules, S.; Khusniyarov, M. M. Chem. Eur. J. 2014, 20, 11149.

(27) Kiriya, D.; Chang, H.-C.; Nakamura, K.; Tanaka, D.; Yoneda, K.; Kitagawa, S. Chem. Mater. 2009, 21, 1980.

(28) Attia; Pierpont, C. G. Inorg. Chem. 1998, 37, 3051.

(29) Attia, A. S.; Pierpont, C. G. Inorg. Chem. 1995, 34, 1172.

(30) Caneschi, A.; Dei, A. Angew. Chem. Int. Ed. 1998, 37, 3005.

(31) Goswami, S.; Panja, A.; Butcher, R. J.; Shaikh, N.; Banerjee, P. Inorg. Chim. Acta 2011, 370, 311.

(32) Kiriya, D.; Nakamura, K.; Chang, H.-C.; Kitagawa, S. Chem. Commun. 2009, 4085.

(33) Starikov, A. G.; Koval, V. V.; Minyaev, R. M.; Minkin, V. I. Dokl Chem 2011, 441, 365.

(34) Rajput, A.; Sharma, A. K.; Barman, S. K.; Koley, D.; Steinert, M.; Mukherjee, R. Inorg. Chem. 2014, 53,

36.

(35) Shaikh, N.; Goswami, S.; Panja, A.; Wang, X.-Y.; Gao, S.; Butcher, R. J.; Banerjee, P. Inorg. Chem. 2004, 43, 5908 .

(36) Ohtsu, H.; Tanaka, K. Angew. Chem. Int. Ed. 2004, 43, 6301.

(37) Mitsumi, M.; Nishitani, T.; Yamasaki, S.; Shimada, N.; Komatsu, Y.; Toriumi, K.; Kitagawa, Y.; Okumura, M.; Miyazaki, Y.; Gorska, N.; Inaba, A.; Kanda, A.; Hanasaki, N. J. Am. Chem. Soc. 2014, 136, 7026.

(38) Bendix, J.; Clark, K. M. Angew. Chem. Int. Ed. 2016, 55, 2748.

(39) Drouza, C.; Vlasiou, M.; Keramidas, A. D. Dalton Trans. 2013, 42, 11831.

(40) Attia; Pierpont, C. G. Inorg. Chem. 1997, 36, 6184.

(41) Jung, O.-S.; Pierpont, C. G. J. Am. Chem. Soc. 1994, 116, 2229.

(42) Shaikh, N.; Goswami, S.; Panja, A.; Sun, H.-L.; Pan, F.; Gao, S.; Banerjee, P. Inorg. Chem. 2005, 44, 9714.

(43) Li, B.; Chen, L.-Q.; Wei, R.-J.; Tao, J.; Huang, R.-B.; Zheng, L.-S.; Zheng, Z. Inorg. Chem. 2010, $50,424$.

(44) Lonnon, D. G.; Lee, S. T.; Colbran, S. B. J. Am. Chem. Soc. 2007, 129, 5800.

(45) Song, Y.; Fan, R.-Q.; Wang, X.-M.; Gao, S.; Du, X.; Wang, P.; Yang, Y.-L. CrystEngComm 2016, $18,1878$.

(46) Mereacre, V.; Schlageter, M.; Powell, A. K. J. Magn. Magn. Mater. 2015, 381, 478.

(47) Ratera, I.; Ruiz-Molina, D.; Renz, F.; Ensling, J.; Wurst, K.; Rovira, C.; Gütlich, P.; Veciana, J. J. Am. Chem. Soc. 2003, 125, 1462. 
(48) Scheja, A.; Baabe, D.; Menzel, D.; Pietzonka, C.; Schweyen, P.; Bröring, M. Chem. Eur. J. 2015, 21, 14196.

(49) Wang, H.; Sun, S.; Wang, H.; King, R. B. New J. Chem. 2016, 40, 1521.

(50) Weiss, R.; Bulach, V.; Gold, A.; Terner, J.; Trautwein, A. X. J. Biol. Inorg. Chem. 2001, 6, 831.

(51) Bougher, C. J.; Liu, S.; Hicks, S. D.; Abu-Omar, M. M. J. Am. Chem. Soc. 2015, 137, 14481.

(52) Leeladee, P.; Baglia, R. A.; Prokop, K. A.; Latifi, R.; de Visser, S. P.; Goldberg, D. P. J. Am. Chem. Soc. 2012, 134, 10397.

(53) Chen, J.; Wuttke, E.; Polit, W.; Exner, T.; Winter, R. F. J. Am. Chem. Soc. 2013, 135, 3391.

(54) Heras, C.; Ramos-Tomillero, I.; Caballero, M.; Paradís-Bas, M.; Nicolás, E.; Albericio, F.; de P. R. Moreira, I.; Bofill, J. M. Eur. J. Org. Chem. 2015, 2015, 2111.

(55) Fedushkin, I. L.; Maslova, O. V.; Morozov, A. G.; Dechert, S.; Demeshko, S.; Meyer, F. Angew. Chem. Int. Ed. 2012, 51, 10584.

(56) Budnikova, Y. G.; Gryaznova, T. V.; Kadirov, M. K.; Tret'yakov, E. V.; Kholin, K. V.; Ovcharenko, V. I.; Sagdeev, R. Z.; Sinyashin, O. G. Russ. J. Appl. Chem. 2009, 83, 1976.

(57) Ressouche, E.; Boucherle, J. X.; Gillon, B.; Rey, P.; Schweizer, J. J. Am. Chem. Soc. 1993, 115, 3610.

(58) Caneschi, A.; Gatteschi, D.; Rey, P. Prog Inorg. Chem 1991, 39, 331.

(59) Luneau, D.; Rey, P. Coord. Chem. Rev. 2005, 249, 2591.

(60) Fegy, K.; Sanz, N.; Luneau, D.; Belorizky, E.; Rey, P. Inorg. Chem. 1998, 37, 4518.

(61) Lescop, C.; Bussiere, G.; Beaulac, R.; Belisle, H.; Belorizky, E.; Rey, P.; Reber, C.; Luneau, D. J. Phys. Chem. Solids 2004, 65, 773.

(62) Lescop, C.; Luneau, D.; Belorizky, E.; Fries, P.; Guillot, M.; Rey, P. Inorg. Chem. 1999, 38, 5472.

(63) Lescop, C.; Luneau, D.; Bussiere, G.; Triest, H.; Reber, C. Inorg. Chem. 2000, 39, 3740.

(64) Lescop, C.; Luneau, D.; Rey, P.; Bussiere, G.; Reber, C. Inorg. Chem. 2002, 41, 5566.

(65) Lannes, A.; Intissar, M.; Suffren, Y.; Reber, C.; Luneau, D. Inorg. Chem. 2014, 53, 9548.

(66) Fegy, K.; Luneau, D.; Belorizky, E.; Novac, M.; Tholence, J.-L.; Paulsen, C.; Ohm, T.; Rey, P. Inorg. Chem. 1998, 37, 4524.

(67) Fegy, K.; Luneau, D.; Ohm, T.; Paulsen, C.; Rey, P. Angew. Chem., Int. Ed. 1998, 37, 1270.

(68) Luneau, D.; Borta, A.; Chumakov, Y.; Jacquot, J.-F.; Jeanneau, E.; Lescop, C.; Rey, P. Inorg. Chim. Acta $2008,361,3669$.

(69) Lacey, A. A.; Price, D. M.; Reading, M. In Modulated temperature differential scanning calorimetry: Theoretical and practical applications in polymer characterisation; Reading, M., Hourston, D. J., Ed.; Springer: Dordrecht, The Netherlands, 2006.

(70) Schawe, J. E. K. Thermochim. Acta 1997, 305, 111.

(71) Brown, R. J. C.; Weir, R. D. Thermochim. Acta 1989, 139, 93.

(72) Chen, G.; Lee, C.; Kuo, Y. L.; Yen, Y. W. Thermochim. Acta 2007, 456, 89.

(73) Gronvold, F.; Stolen, S.; Westrum, E. F.; Galeas, C. G. J. Chem. Thermodyn. 1987, 19, 1305.

(74) Massa, W. Rev. Inorg. Chem. 1999, 19, 117.

(75) Jones, L. F.; Rajaraman, G.; Brockman, J.; Murugesu, M.; San̂udo, E. C.; Raftery, J.; Teat, S. J.; Wernsdorfer, W.; Christou, G.; Brechin, E. K.; Collison, D. Chem. Eur. J. 2004, 10, 5180.

(76) Pebler, J.; Frommen, C.; Mangold, M.; Stief, R.; Krimmel, A.; van de Kamp, R.; Ohl, M.; Regnault, L.-P. Z. Anorg. Allg. Chem. 2004, 630, 829.

(77) Thorp, H. H. Inorg. Chem. 1992, 31, 1585.

(78) Caneschi, A.; Gatteschi, D.; Renard, J. P.; Rey, P.; Sessoli, R. Inorg. Chem. 1989, 28, 3314.

(79) Caneschi, A.; Gatteschi, D.; Rey, P.; Sessoli, R. Inorg. Chem. 1991, 30, 3936.

(80) Caneschi, A.; Gatteschi, D.; Sessoli, R. Inorg. Chem. 1993, 32, 4612.

(81) Liu, R.-N.; Li, L.-C.; Xing, X.-Y.; Liao, D.-Z. Inorg. Chim. Acta 2009, 362, 2253.

(82) Li, Y.; Guo, Y.; Tian, H.; Hu, P.; Sun, Z.; Ma, Y.; Li, L.; Liao, D. Inorg. Chem. Commun. 2014, 43, 135.

(83) Benson, S. W. J. Chem. Ed. 1965, 42, 502. 
(84) Bersuker, I. B. Chem. Rev. 2001, 101, 1067.

(85) Cook, L. J. K.; Thorp-Greenwood, F. L.; Comyn, T. P.; Cespedes, O.; Chastanet, G.; Halcrow, M. A. Inorg. Chem. 2015, 54, 6319.

(86) Halcrow, M. A. Chem. Soc. Rev. 2011, 40, 4119.

(87) Bussiere, G.; Beaulac, R.; Belisle, H.; Lescop, C.; Luneau, D.; Rey, P.; Reber, C. Topics Curr. Chem. 2004, $241,97$.

(88) Rintoul, L.; Micallef, A. S.; Bottle, S. E. Spectrochim. Acta A 2008, 70, 713.

(89) Zoppellaro, G.; Ivanova, A.; Enkelmann, V.; Geies, A.; Baumgarten, M. Polyhedron 2003, $22,2099$.

(90) Suffren, Y.; Rollet, F.-G.; Reber, C. Comments Inorg. Chem. 2011, 32, 246.

(91) Gupta, R.; Taguchi, T.; Borovik, A. S.; Hendrich, M. P. Inorg. Chem. 2013, 52, 12568.

(92) Duboc, C. Chem. Soc. Rev. 2016, 45, 5834.

(93) Proux, O.; Biquard, X.; Lahera, E.; Menthonnex, J. J.; Prat, A.; Ulrich, O.; Soldo, Y.; Trevisson, P.; Kapoujyan, G.; Perroux, G.; Taunier, P.; Grand, D.; Jeantet, P.; Deleglise, M.; Roux, J. P.; Hazemann, J. L. Phys. Scripta 2005, T115, 970.

(94) Kadirov, M. K.; Tretyakov, E. V.; Budnikova, Y. G.; Kholin, K. V.; Valitov, M. I.; Vavilova, V. N.; Ovcharenko, V. I.; Sagdeev, R. Z.; Sinyashin, O. G. Russ. J. Appl. Chem. 2009, 83, 2163. 


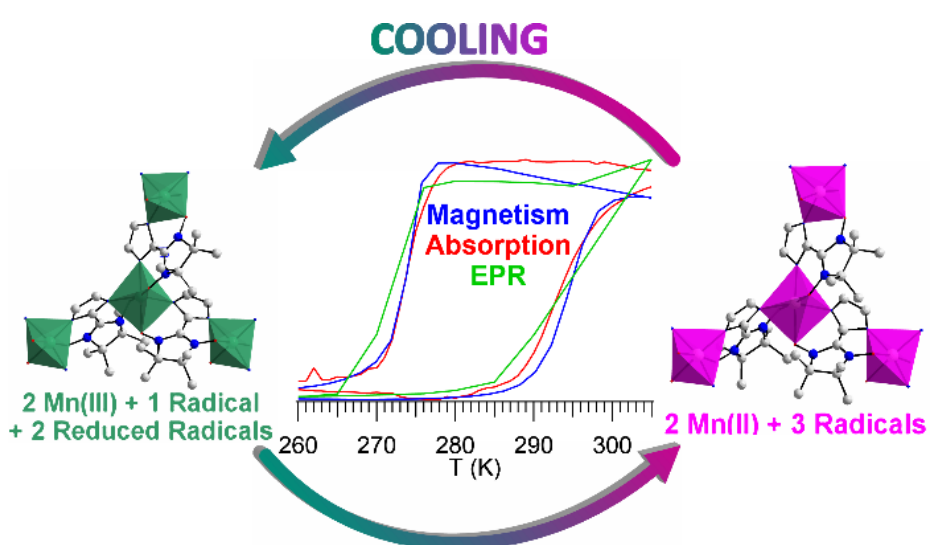

HEATING 